\title{
COMBINED ACTION OF DIAMOX AND POTASSIUM BICARBONATE IN THE TREATMENT OF CHRONIC GLAUCOMA*
}

BY

\author{
D. A. CAMPBELL, M. JONES, N. E. A. RENNER, AND E. L. TONKS \\ From the Research Department, Birmingham and Midland Eye Hospital
}

Ir has been well established that Diamox causes excretion of cations, especially sodium and potassium, and that in conditions of sodium depletion potassium may be excreted in place of sodium (Milne, 1956). In fact the administration of potassium bicarbonate will increase the systemic effects of Diamox.

We have already drawn attention to the correlation between cation excretion and fall in intra-ocular pressure after Diamox (Campbell, Jones, and Tonks, 1956), and were therefore interested to discover whether potassium bicarbonate would have a potentiating effect on the action of Diamox in cases of chronic glaucoma.

In common with other observers (Becker and Middleton, 1955; Kupfer, Lawrence, and Linnér, 1955), we have noticed that patients under treatment with Diamox often complain of paraesthesia and that this symptom is sometimes associated with a relatively low level of blood potassium. It is interesting to note in this respect that Becker and Middleton have reported the relief of paraesthesia and other side-effects by the addition of potassium chloride given by mouth.

On a pharmacological basis, the continued use of Diamox could not be expected to be beneficial in the treatment of chronic glaucoma, since a single dose engenders a state of acidosis from which the body may take 2 to 3 days to recover (Maren and Wadsworth, 1955; Hanley and Platts, 1956). In fact, Arruga (1955) pointed out that, whenever Diamox has been used over long periods with success, it has always been employed in combination with miotics. It is highly probable that the latter masked the diminishing effect of Diamox. Our experiments were designed to elucidate this point as well as to investigate the effects of the addition of a potassium salt.

\section{Experiments}

We made a detailed study of the effect of Diamox in three patients affected with open angle glaucoma. They were selected from the glaucoma clinic

* Received for publication May 17, 1957. 
because they were unwilling to undergo any further surgical treatment, and their glaucoma had ceased to be controlled adequately either by miotics. alone, or by the administration of Diamox in frequent doses (usually $250 \mathrm{mg}$. once or twice daily). In each patient renal function was normal.

On admission the patients were given a uniform diet as described previously (Campbell, Tonks, and Jones, 1956). The food and water intake was recorded, the sodium intake being not more than $44 \mathrm{mEq}$. in 24 hours, and the water intake being controlled so as to maintain a regular state of hydration.

The following investigations were made in sequence:

(a) Diurnal variation of the intra-ocular pressure, in the resting state (mm. Hg Schiötz).

(b) A study of the effect upon intra-ocular pressure of a daily single dose of $250 \mathrm{mg}$. Diamox on consecutive days.

(c) A study of the combined effect of Diamox ( $250 \mathrm{mg}$. daily) and potassium bicarbonate ( $1 \mathrm{~g}$. three times a day) administered at 7 a.m., 2 p.m., and 7 p.m.

(d) The correlation of the effects of Diamox on intra-ocular pressure with systemic effects, in respect of the variations in urinary volume, and sodium and potassium excretion.

\section{Case Histories}

Case 1 (Unoperated Bilateral Glaucoma) in a woman aged 72 who was under continuous. observation for a period of 20 months before admission.

When first seen (5.5.54) she complained of poor visual acuity in the right eye.

Right Eye.-Visual acuity counting fingers, not improved by glasses. Cupped disc. Ocular tension $56 \mathrm{~mm}$. Hg. Virtually no residual field.

Left Eye.-Visual acuity 6/18, with glasses 6/9. Normal ocular tension. Full field.

Intra-ocular pressure in the right eye responded to 1 per cent. eserine drops, and one week later the ocular tension was $28 \mathrm{~mm}$. $\mathrm{Hg}$ in the right eye and $32 \mathrm{~mm}$. $\mathrm{Hg}$ in the left eye. The drops were then prescribed for both eyes. Intra-ocular pressure remained unchanged for 3 months, when eserine irritation developed, and the drops were changed to 2 per cent. pilocarpine. The intra-ocular pressure appeared to be controlled satisfactorily until November, 1955 , when it rose to $40 \mathrm{~mm}$. $\mathrm{Hg}$ in the right eye. It was again controlled by the addition of 0.5 per cent. eserine to the 2 per cent. pilocarpine drops.

The patient was transferred to the Glaucoma Clinic in January, 1956, when her afternoon records of intra-ocular pressure were found to be unexpectedly high, viz. right eye 40 , left eye $35 \mathrm{~mm}$. Hg. She was given Diamox $250 \mathrm{mg}$. daily and eserine 0.5 per cent. in the right eye, and pilocarpine 2 per cent. in the left eye three times a day. The intraocular pressure was reduced after one week to $28 \mathrm{~mm}$. $\mathrm{Hg}$ and at the end of a month to $24 \mathrm{~mm}$. Hg in each eye. Diamox was then reduced to $250 \mathrm{mg}$. every other day, and the intra-ocular pressure was controlled for a period of 3 months.

On May 9, 1956, she complained of severe tingling 4 hours after taking Diamox and was found to have a rather low blood potassium $(4.1 \mathrm{mEq}$. per cent. compared with the normal range of 4.4 to $5.6 \mathrm{mEq}$. per cent). The intra-ocular pressure was taken in the 
afternoon and found to be $30 \mathrm{~mm}$. $\mathrm{Hg}$ in each eye, and she was therefore admitted for fuller investigation. At this time the visual acuity in the right eye was perception of light; in the left eye it was $6 / 9$ with slight contraction of field. Both eyes still showed an open angle on gonioscopy.

(a) Diurnal Variation.-Records of intra-ocular pressure were taken for a period of 4 days with the patient at rest in bed and receiving no treatment. Fig. 1(a) shows that there were wide excursions in the intra-ocular pressure which tended to lessen with rest.

(b) Effect of Diamox Alone.-There was a tendency for the intra-ocular pressure to rise in the late afternoon, so that Diamox $(250 \mathrm{mg}$.) was given at 4 p.m.

On the first day there was a good response, but on the second day the response was almost negligible (Fig. 1b), i.e. the patient very quickly became resistant. After an interval of 3 days Diamox again produced a response, but the intra-ocular pressure rose again above the initial level in less than 24 hours.

(c) Effect of Diamox plus Potassium Bicarbonate.-The addition of potassium bicarbonate $1 \mathrm{~g}$. three times daily produced a well-sustained response to a daily dose of Diamox (Fig. 1c). The patient was discharged on this treatment without miotics.

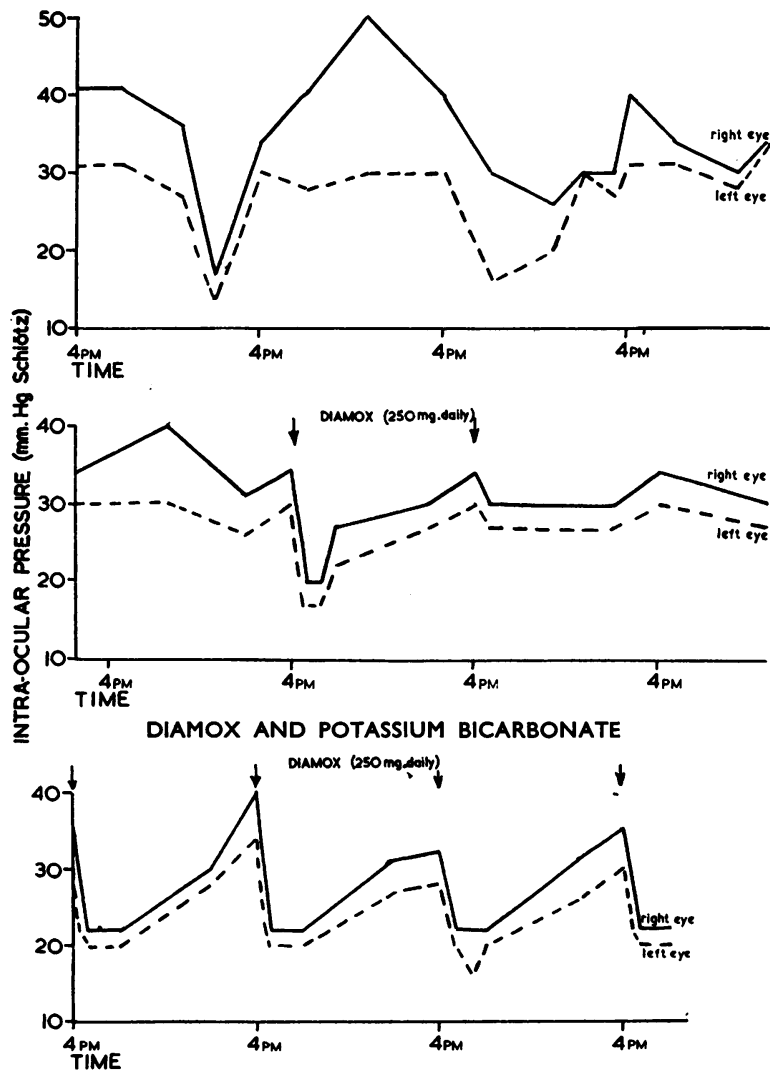

Fig. 1(a).-Case 1, diurnal väriation in intra-ocular pressure.

Fig. 1(b).-Case 1, diminishing effects of Diamox.

Fig. 1(c).-Case 1, adjuvant effect of potassium bicarbonate $1 \mathrm{~g}$. three times a day. 
Subsequent Progress.-Later tests were conducted as an out-patient, intra-ocular pressure being recorded before, and 1 hour after, a dose of Diamox, given on each occasion at the appropriate time (Table).

TABLE

PROGRESS OF CASE 1 ON DIAMOX AND POTASSIUM BICARBONATE

\begin{tabular}{|c|c|c|c|c|c|}
\hline \multirow{3}{*}{ Date } & \multirow{3}{*}{$\begin{array}{c}\text { Time of Dose } \\
\text { (p.m.) }\end{array}$} & \multicolumn{4}{|c|}{ Intra-Ocular Pressure (mm. Hg) } \\
\hline & & \multicolumn{2}{|c|}{ Before Diamox } & \multicolumn{2}{|c|}{$\begin{array}{c}1 \mathrm{hr} \text { after Diamox } \\
(250 \mathrm{mg} .)\end{array}$} \\
\hline & & Right & Left & Right & Left \\
\hline 7.6.56 & $\begin{array}{l}4.0 \\
5.0\end{array}$ & 41 & 31 & 35 & 27 \\
\hline 22.6 .56 & $\begin{array}{l}2.30 \\
3.30\end{array}$ & 35 & 31 & 27 & 23 \\
\hline 5.8 .56 & $\begin{array}{l}3.0 \\
4.0\end{array}$ & 25 & 28 & 20 & 23 \\
\hline 10.8 .56 & $\begin{array}{l}3.0 \\
4.0\end{array}$ & 26 & 23 & 23 & 20 \\
\hline 24.8.56* & 3.0 & 26 & 23 & & \\
\hline 7.9.56 & 3.30 & 24 & 27 & & \\
\hline 15.10 .56 & 3.45 & 27 & 23 & & \\
\hline 7.12.56 & 3.0 & 25 & 22 & & \\
\hline 15.2.57 & 3.30 & 23 & 20 & & \\
\hline
\end{tabular}

* Further tests with Diamox were unnecessary from this date.

On a combined therapy of Diamox and potassium bicarbonate, progress has been quite satisfactory for 8 months. The visual acuity in the left eye is still $6 / 9$, with no further loss in the visual field, and the blood potassium and sodium have remained within normal limits.

Case 2 (Bilateral Glaucoma with Iridencleisis in the Left Eye) in a woman aged 64 who first attended hospital on September 9, 1955, complaining of deterioration of vision in the left eye.

Right Eye.-Visual acuity 6/24. Intra-ocular pressure $25 \mathrm{~mm}$. Hg. Visual field reduced to half; mainly temporal loss. Early cupping of the disc.

Left Eye.-Visual acuity 6/36. Intra-ocular pressure $56 \mathrm{~mm}$. Hg. Total loss of nasal visual field with reduction of temporal field. Marked cupping. Steamy cornea.

Gonioscopy showed an open angle in both eyes.

She was admitted on the same day for intensive treatment of left eye with eserine. The intra-ocular pressure fell to $40 \mathrm{~mm}$. $\mathrm{Hg}$, and with one dose of $250 \mathrm{mg}$. Diamox to 30 , but rose again to $60 \mathrm{~mm}$. Hg. Left iridencleisis was therefore performed on the third day. The intra-ocular pressure remained high for 9 days, and was reduced by a daily dose of Diamox $250 \mathrm{mg}$. On discharge on the 19th day intra-ocular pressure was $35 \mathrm{~mm}$. $\mathbf{H g}$ 
and it finally fell to 28 on continuation of the same treatment by the 21 st day. Diamox was discontinued and 1 per cent. pilocarpine drops substituted, but the intra-ocular pressure rose again to $56 \mathrm{~mm}$. $\mathrm{Hg}$ after 2 weeks and could not be controlled by increasing the strength of pilocarpine to 2 per cent.

On November 1, 1955, Diamox $250 \mathrm{mg}$. twice a day and pilocarpine 2 per cent. were resumed. The intra-ocular pressure remained normal (25) for over 3 months. Diamox was then discontinued and the pilocarpine reduced to 1 per cent., but on April 6, 1950, the intra-ocular pressure again rose to $45 \mathrm{~mm}$. Hg. Diamox $250 \mathrm{mg}$. every other day was again effective and further operation was not considered.

The intra-ocular pressure in the right eye had so far given no cause for concern, but on April 20, 1956, it rose to $32 \mathrm{~mm}$. $\mathrm{Hg}$. It so happened that the patient was now attending in the afternoon whereas the previous records had been made at a morning clinic. She was therefore admitted on April 23, 1956, to the Research Department for observation.

(a) Diurnal Variation.-With rest in bed and no treatment, the intra-ocular pressure did not rise above $34 \mathrm{~mm}$. $\mathrm{Hg}$ in the left eye and $28 \mathrm{~mm}$. $\mathrm{Hg}$ in the right eye for 2 days, but was highest each day in the late afternoon. On the morning of the third day the left eye developed acute glaucoma. A dose of Diamox produced an immediate fall in intra-ocular pressure, but in the afternoon eserine 0.5 per cent. had to be used in the left eye, and two more doses of Diamox were given, one at 4.30 p.m. which was immediately vomited, and a second at 8 p.m. with good effect.

(b) Effect of Repeated Daily Doses of Diamox (Fig. 2a, opposite).-After an interval of 4 days, when the patient remained at rest, dosage with Diamox was resumed. It was administered at 4 p.m. each day, i.e. at the time when the intra-ocular pressure began to rise. The diminishing effect of daily repetition of the drug is particularly well seen in the case of the right eye. The intra-ocular pressure in the left eye was barely affected and had to be controlled by the additional use of eserine drops at 10 p.m.

Once again, after 2 days without Diamox, the left eye developed acute glaucoma. The intra-ocular pressure rose again to $61 \mathrm{~mm}$. $\mathrm{Hg}$ and had to be reduced with intensive eserine. The intra-ocular pressure in the right eye rose at the same time to $40 \mathrm{~mm}$. $\mathrm{Hg}$. It was therefore decided to explore the effect of potassium bicarbonate as an adjuvant.

(c) Effect of Diamox plus Potassium Bicarbonate (Fig. 2b, opposite).-In the 4 successive days immediately following the acute rise in tension, the patient was given a daily dose of $250 \mathrm{mg}$. Diamox at $4 \mathrm{p} . \mathrm{m}$. together with $1 \mathrm{~g}$. potassium bicarbonate at 7 a.m., 2 p.m., and 7 p.m. There was a striking improvement in the response to Diamox and a steady decline in the maximum intra-ocular pressure in both eyes.

The patient was discharged on this treatment, and on two occasions in the glaucoma clinic (after intervals of one week and of 3 weeks) the intra-ocular pressure fell to 17 and $20 \mathrm{~mm}$. $\mathrm{Hg}$ in the right and left eyes respectively, $2 \frac{1}{2}$ hours after a test dose of Diamox.

A further check as an in-patient 2 months later showed that the control of intra-ocular pressure was well maintained even without miotics. In this test potassium biphosphate in doses of $2 \mathrm{~g}$. three times a day was substituted for potassium bicarbonate. Its effect was slightly less marked than that of potassium bicarbonate.

The patient has continued under treatment with Diamox and potassium bicarbonate for a total period of 8 months. Her blood potassium has remained within normal limits, and except for one occasion the intra-ocular pressure in the left eye has not risen above $25 \mathrm{~mm}$. $\mathrm{Hg}$, and that of the right eye above $20 \mathrm{~mm}$. $\mathrm{Hg}$. The visual acuity (with correction) is $6 / 18$ in the right eye and 6/60 in the left eye. The visual field in the right eye shows no further loss. 


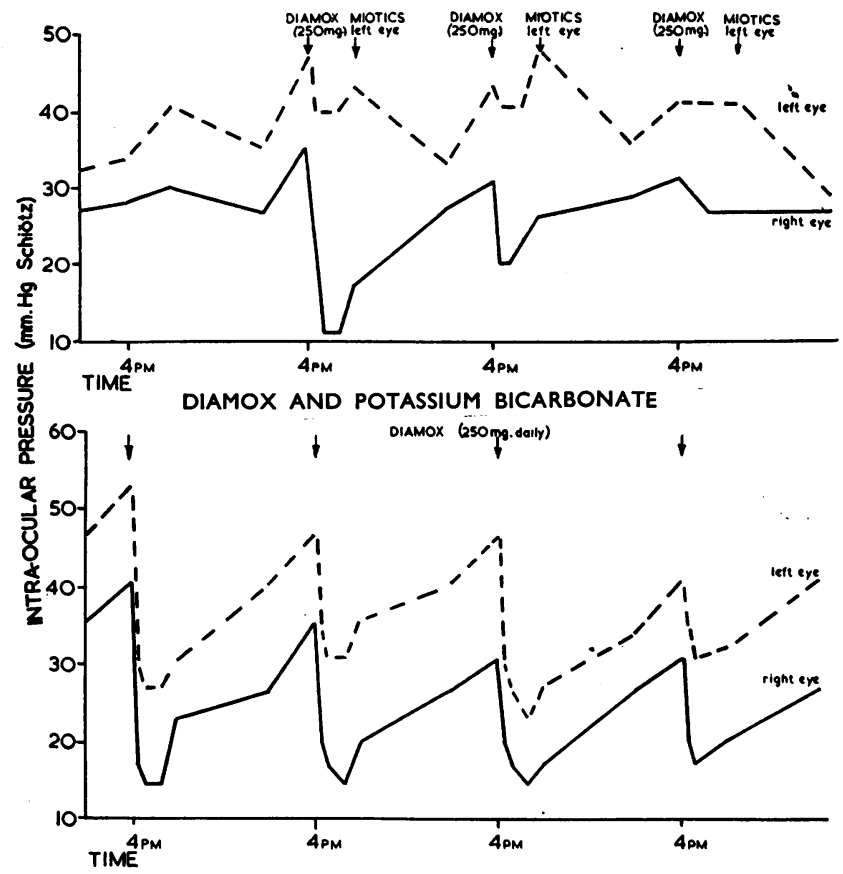

FIG. 2(a).-Case 2, diminishing effects of Diamox.

Fig. 2(b).-Case 2, adjuvant effect of potassium bicarbonate, $1 \mathrm{~g}$. three times a day.

Case 3 (Bilateral Glaucoma - with Non-filtering Iridencleisis in the Right Eye, and Iridencleisis plus Cyclodialysis giving Active Filtration in the Left Eye) in a man aged 45 who had been under continuous observation for 8 years before coming to the glaucoma clinic.

His initial state in 1948 was visual acuity $6 / 9$ and intra-ocular pressure $40 \mathrm{~mm}$. $\mathrm{Hg}$ in the right eye, and visual acuity $6 / 18$ and intra-ocular pressure $35 \mathrm{~mm} . \mathrm{Hg}$ in the left eye.

On gonioscopy both eyes had an open angle. Both visual fields were full, and the optic discs showed early glaucomatous cupping.

He was treated with miotics for several months until early in 1949 when the intraocular pressure rose again to $40 \mathrm{~mm}$. $\mathrm{Hg}$ in each eye. Bilateral iridencleisis was performed but miotics were necessary post-operatively.

In November, 1954, the left eye developed acute glaucoma, the intra-ocular pressure being $48 \mathrm{~mm}$. $\mathrm{Hg}$, and a cyclodialysis was performed followed by a paracentesis 6 weeks later. After this, filtration was maintained in the left eye, but the right still required treatment with miotics. There was only a slight loss in the nasal fields after 7 years' treatment, but the visual acuity had diminished to $6 / 18$ in the right eye and 6/36 in the left.

In January, 1956, the intra-ocular pressure rose to $45 \mathrm{~mm}$. $\mathrm{Hg}$ in the right eye and $32 \mathrm{~mm}$. $\mathrm{Hg}$ in the left. On this occasion it responded immediately to Diamox. A maintenance dose of $250 \mathrm{mg}$. every other day was continued for 4 months, miotics being still necessary in the right eye. The visual acuity was adversely affected by the miotics, and in May, 1956, the patient complained that his vision became misty every afternoon. At this point he was admitted to the Research Department for fuller investigation.

Diurnal Variation and Response to Diamox

(a) In the resting state the intra-ocular pressure was observed to rise each day soon after 11 a.m. (Fig. $3 a$, overleaf). 
(b) The administration of $250 \mathrm{mg}$. Diamox at this hour on two successive days (Fig. $3 b$ ) met with a diminishing response.

(c) The daily fall in intra-ocular pressure was enhanced and sustained by the addition of $1 \mathrm{~g}$. potassium bicarbonate three times a day (Fig. $3 c$ ).
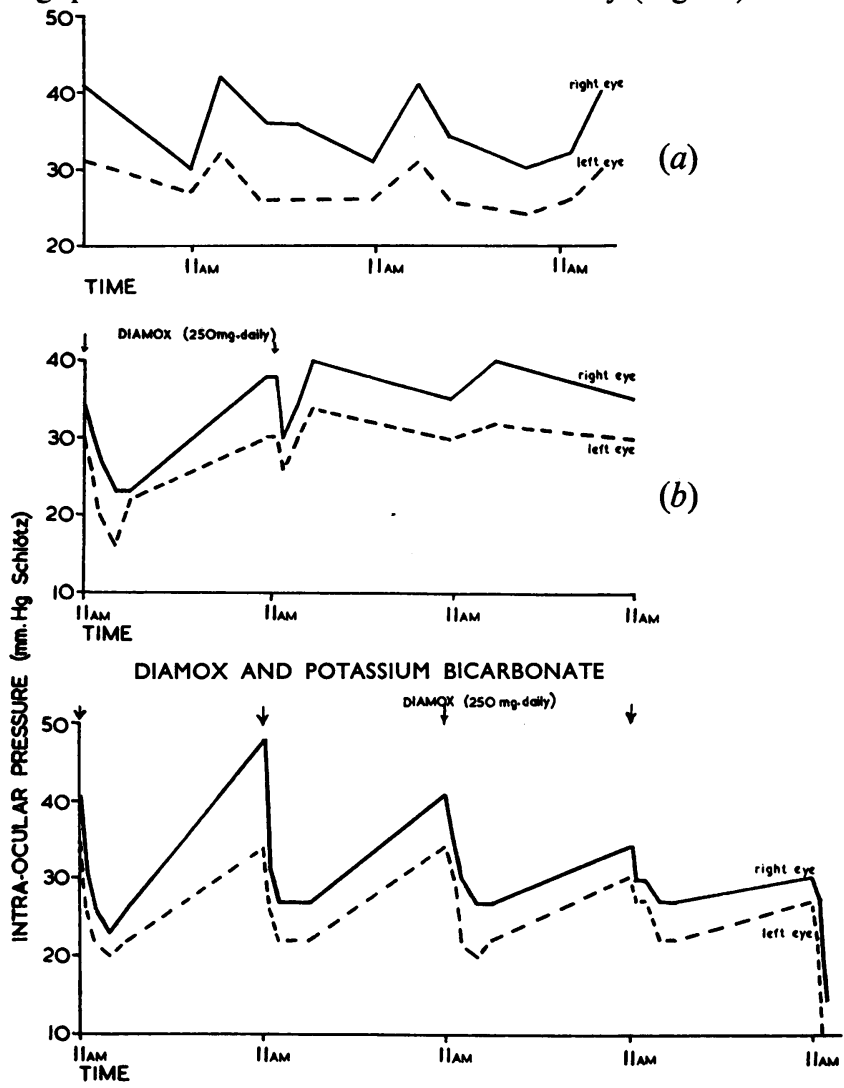

(c)

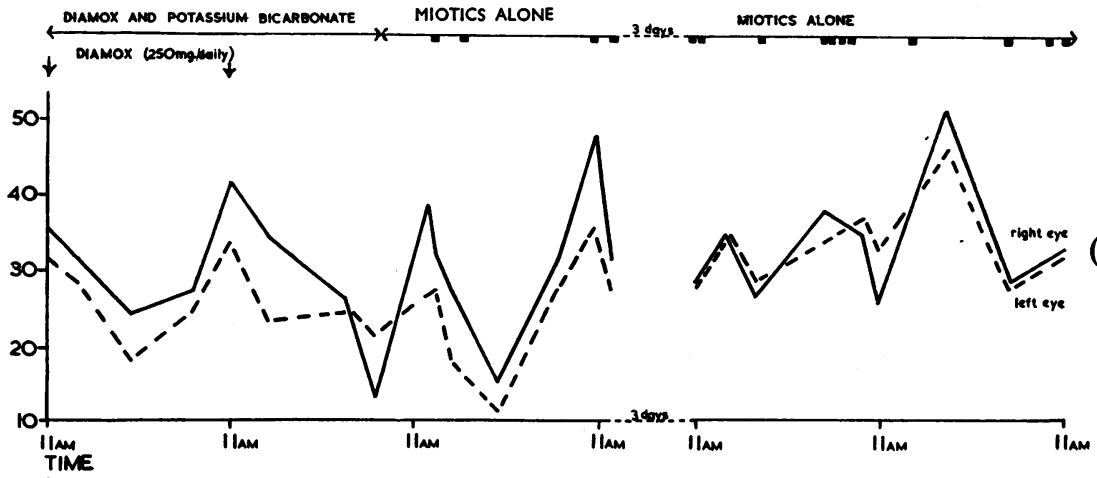

Fig. 3(a).-Case 3, diurnal variation in intra-ocular pressure.

Fig. 3(b).-Case 3, diminishing effect of Diamox.

Fig. 3(c).-Case 3, effect of Diamox and potassium bicarbonate $1 \mathrm{~g}$. three times a day.

Fig. 3(d).-Case 3, repeated test showing rise in intra-ocular pressure after withdrawal of Diamox and potassium bicarbonate even with use of miotics. 
The patient was discharged on this treatment and his condition remained satisfactory for 3 months, when on October 1 his blood potassium was found to be $22 \mathrm{mg}$. per cent. On testing him again as an in-patient, we found that on the first day Diamox alone promoted a reasonable fall in intra-ocular pressure, while with potassium bicarbonate on subsequent days there were very large excursions (Fig. 3d). On withdrawal of both drugs the diurnal variation increased in extent for a few days, but with the succeeding rise in tension it was again necessary to use miotics to control the peaks.

\section{Correlation of the Intra-Ocular and Systemic Effects of Diamox}

For the sake of brevity the three cases are considered together:

(a) In each case the systemic reaction to Diamox followed the pattern previously described by Campbell, Tonks, and Jones (1956).

(b) With repeated daily doses the diminishing effect on intra-ocular pressure was accompanied by a diminishing excretion of urine and of sodium. This was evident not only in the first 6 hours immediately after taking Diamox (Fig. 4, overleaf), but also in the total excretion for 24 hours. As sodium was conserved, potassium excretion increased.

(c) In cases treated with potassium bicarbonate the excretion of potassium was of course increased (Fig. 5, overleaf) and that of sodium markedly decreased. Diuresis was well sustained.

(d) A striking correlation was seen between the $\mathrm{pH}$ of the urine and the intra-ocular pressure (Figs 6 and 7, overleaf). A fall in the latter coincided with a marked increase in alkalinity of the urine.

\section{Results}

It is evident that solitary records of intra-ocular pressure taken in the out-patient department are not a true indication of the progress of the disease, unless they are recorded at the time when the "peak" of intra-ocular pressure normally occurs. This varies in individual cases and can only be discovered by recording the diurnal variation for several days in the resting state as an in-patient. Diamox can then be administered subsequently at the optimum time, i.e. when the intra-ocular pressure is beginning to rise.

It is advisable to discover the degree of response to a particular dose of Diamox. Each of our three cases, on empirical treatment with Diamox before admission, had shown a decline in response to treatment, and this was confirmed by the test. There was a diminishing fall in intra-ocular pressure on successive days when Diamox was administered. This phenomenon was associated with a decline in the systemic effect, as shown by a decrease in diuresis, decreased excretion of sodium, and a return to acidity of the urine. The significance of the correlation of these changes is discussed later.

The addition of potassium bicarbonate in doses of $1 \mathrm{~g}$. three times daily proved surprisingly successful in combination with one daily dose of $250 \mathrm{mg}$ Diamox. Not only were the "side-effects" prevented, but the intra-ocular 

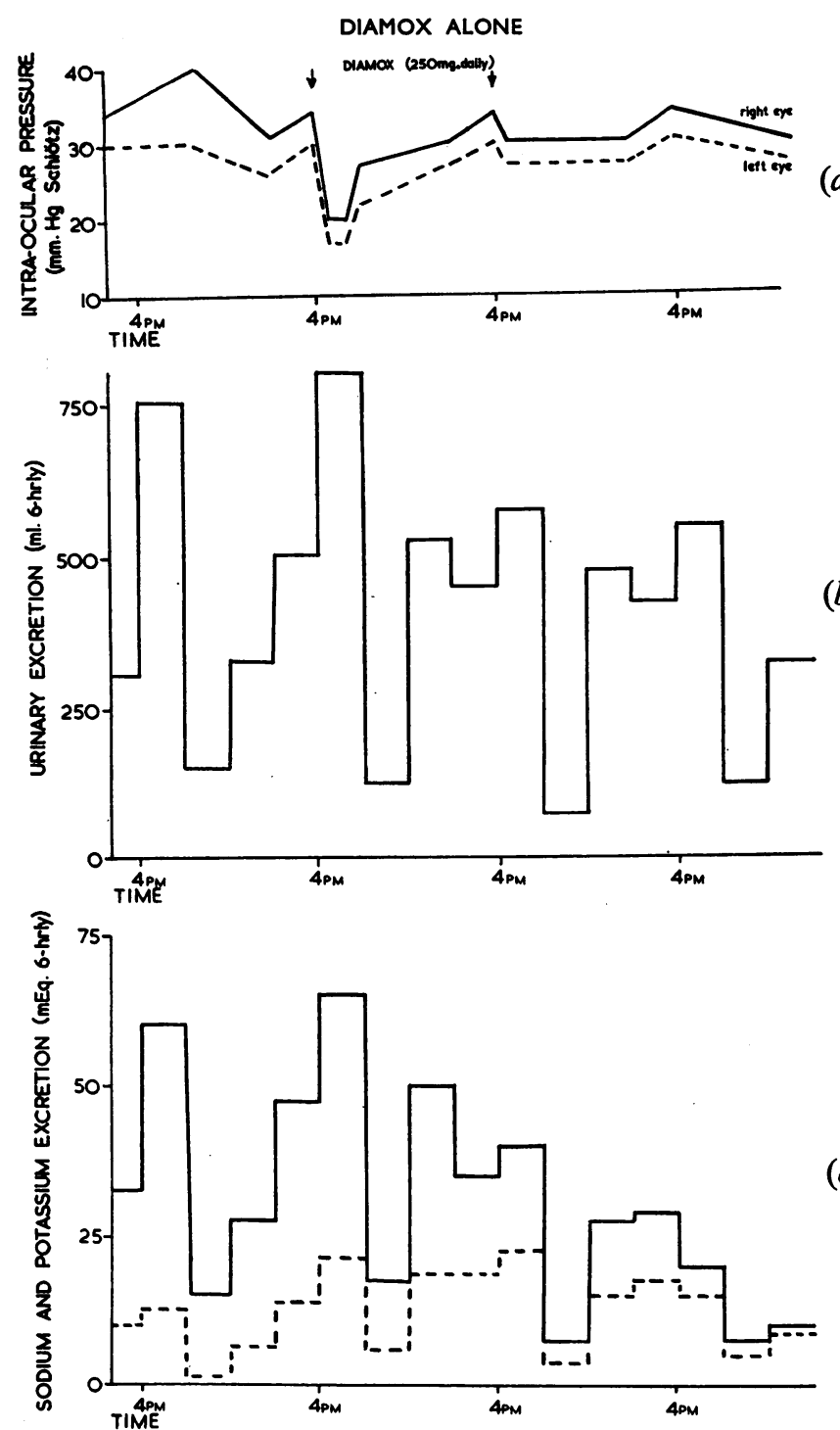

pressure was controlled. The patients were discharged on this treatment and when they were re-tested in hospital after an interval of 2 to 3 months the response was found to be maintained. Two of them (Cases 1 and 2) had shown no abnormal rise in intra-ocular pressure and no side-effects over a total period of 3 months. In the third case the dose of potassium bicarbonate had to be decreased, as he was found to have a rather high level of blood potassium after 2 months.

Fig. 4.-Case 1, diminishing effect of Diamox on: (a) intra-ocular pressure, $(b)$ urinary excretion, $(c)$ sodium and potassium excretion. 


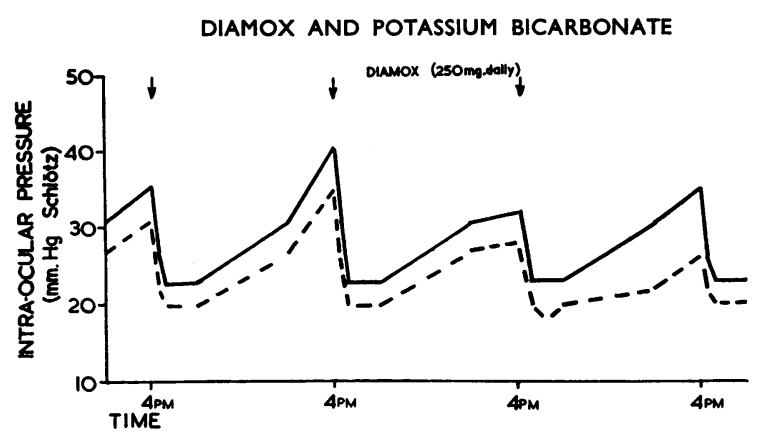

(a)

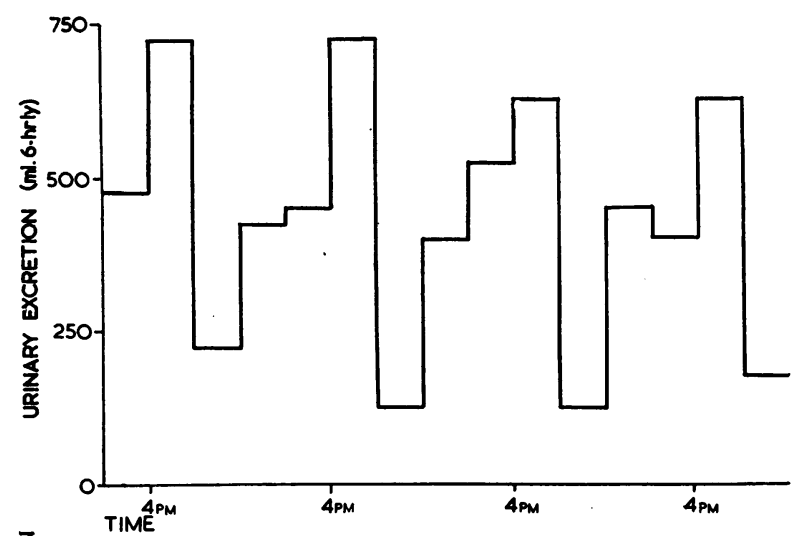

(b)

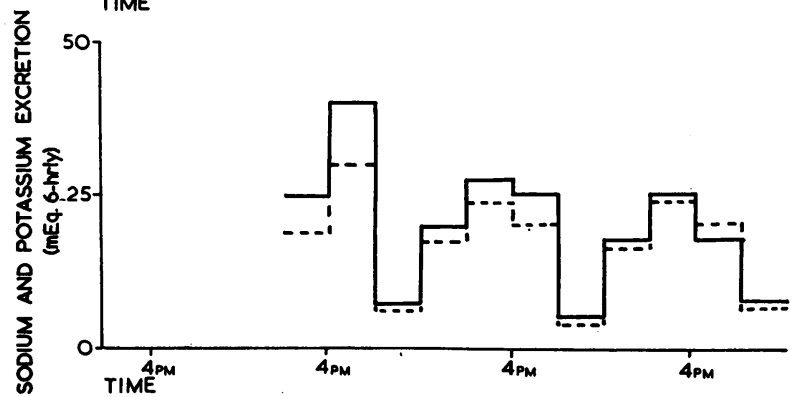

(c)

Fig. 5.-Case 1, effect of Diamox and potassium bicarbonate $1 \mathrm{~g}$. three times a day on: (a) intra-ocular pressure, $(b)$ urinary excretion, (c) sodium and potassium excretion.

In the follow-up of cases, the intra-ocular pressure was also checked in the out-patient department as described in Case 1, and blood potassium estimates were carried out at intervals of a few weeks.

Therapy with Diamox must be confined to individuals in whom there is no abnormality of renal function.

\section{Discussion}

The problem of resistance to Diamox is an interesting one, and as Breinin and Görtz (1954) have pointed out, it is "one of the most characteristic 

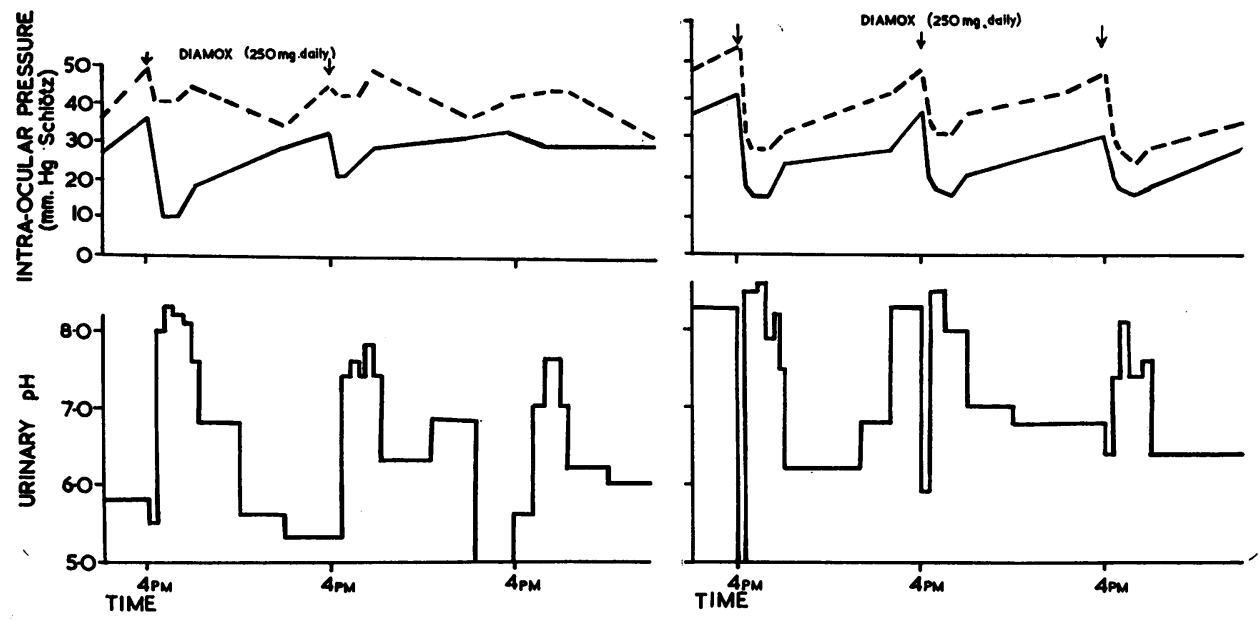

FIG. 6.-Effect of Diamox alone on: (a) intraocular pressure, (b) urinary $\mathrm{pH}$.

FIG. 7.-Effect of Diamox and potassium bicarbonate ( $1 \mathrm{~g}$. three times a day) on: $(a)$ intra-ocular pressure, $(b)$ urinary $\mathrm{pH}$.

findings in acetazolamide medication and constitutes the central problem towards which research must be directed". In the light of this statement the assertion made by Becker and Middleton (1955) that "it now appears firmly established that selected patients with otherwise uncontrolled glaucoma can be maintained (on Diamox) without loss of vision or field and without significant systemic or ocular toxicity" is a misleading one, particularly as the majority of their cases received miotics as well as Diamox.

In other spheres Diamox has been employed as a diuretic, e.g. in cases of cardiac oedema, and there is abundant evidence that its action is self-limiting (Counihan, Evans, and Milne, 1954). The increase in urinary volume, increase in urinary $\mathrm{pH}$, and increased excretion of bicarbonate, sodium, and potassium which it promotes initially all decline when it is given in repeated daily doses.

The relationship of the systemic changes to the changes in intra-ocular pressure is not yet fully known, but there is a parallel response in both after a single dose of Diamox (Campbell, Tonks, and Jones, 1956), and this response diminishes in both after repeated daily doses as shown by our present results. These phenomena occur in both unoperated and operated eyes.

The self-inhibiting effect of Diamox is said to be entirely due to a reduction of the filtered glomerular load of bicarbonate secondary to the systemic acidosis produced (Counihan, Evans, and Milne, 1954), and excretion of bicarbonate is said to fail when the bicarbonate plasma level falls below $16 \mathrm{mEq} / 1$. Maren (1955), on the other hand, states that it is the total quantity of base lost or net body acidosis which inhibits the renal effect. 
Hanley (1956) has shown that continued administration of Diamox after resistance has set in will maintain the depression of plasma bicarbonate and the systemic acidosis, but will not cause any further excretion of bicarbonate.

The adjuvant effect of an increased potassium bicarbonate intake may therefore be due either to the addition of "base" or to added bicarbonate ion. Our test in Case 2, when potassium biphosphate was used in place of potassium bicarbonate, suggests that it may be due to added "base".

The kidney has the ability to conserve sodium or potassium as required; e.g. in dietary sodium depletion it favours excretion of potassium bicarbonate (Counihan and others, 1954), and in potassium deficiency it favours sodium excretion (Evans, Hughes-Jones, Milne, and Steiner, 1954). Our patients were maintained on a comparatively low sodium intake and the administration of potassium bicarbonate therefore favoured the conservation of sodium.* It is interesting to compare this with the finding of Kinsey, Camacho, Cavanaugh, Constant, and McGinty (1955) that rabbits, which were resistant to the action of Diamox and showed no fall in intra-ocular pressure, were made responsive by giving them an increased amount of salt in their diet.

Obviously the problem of the distribution of electrolytes in relation to the maintenance of intra-ocular pressure is a fascinating one. The distribution of the ionic constituents of the aqueous humor after Diamox (Langham and Lee, 1955, 1957; Falbriard, Sanz, Zender, and Franceschetti, 1955) suggests that its effect on the intra-ocular pressure is not the direct outcome of the inhibitory effect of the drug on carbonic anhydrase but is probably due to an alteration in the osmotic balance between the blood and aqueous humour, independent of its renal action. Duke-Elder, Perkins, and Langham (1956) have suggested that the effect of Diamox on intra-ocular pressure arises from a decrease in the base-binding capacity of the blood below normal, which in turn results in a lowered rate of formation of intra-ocular fluid.

\section{Summary}

(1) The effects of a daily dose of $250 \mathrm{mg}$. Diamox have been examined in relation to the problem of "resistance" to the action of the drug.

(2) A diminishing fall in intra-ocular pressure on successive days corresponded with a decline in the systemic effects of the drug as shown by the changes in the pattern of urinary excretion.

(3) The administration of potassium bicarbonate in doses of $1 \mathrm{~g}$. three times a day, together with $250 \mathrm{mg}$. Diamox daily, restored the response and proved effective in controlling the intra-ocular pressure for a considerable period. It also prevented the occurrence of unpleasant side-effects.

(4) This treatment has certain advantages over the use of Diamox combined with miotics, but before it is adopted it is recommended that

* A similar state of affairs continues under Diamox therapy (Milne, 1956). 
investigations should be carried out with the patient in hospital in respect of urinary function, diurnal variation of intra-ocular pressure, and the response of the individual to Diamox and potassium bicarbonate.

(5) During treatment the intra-ocular pressure and the blood potassium should be estimated at regular intervals.

(6) The mechanism of the combined action of Diamox and of potassium bicarbonate on intra-ocular pressure is discussed in relation to its systemic effects.

Our thanks are due to Mr. Archer-Hall and Mr. Charles Rudd, for permission to investigate their cases, and to Mrs. Eva Nelson for technical assistance.

\section{REFERENCES}

ARRUGA, H. (1955). Arch. Soc. oftal. hisp.-amer., 15, 374.

BeCKER, B., and MiDDLETON, W. H. (1955). A.M.A.Arch. Ophthal., 54, 187.

BREININ, G. M., and GörTZ, H. (1954). Ibid., 52, 333.

CAMPBell, D. A., Tonks, E. L., and Jones, M. (1956). British Journal of Ophthalmology, 40, 283.

Couninan, T. B., Evans, B., and MilNe, M. D. (1954). Clin. Sci., 13, 583.

Duke-Elder, S., Perkins, E. S., and Langham, M. E. (1956). Arch. Soc. oftal. hisp.-amer., $16,259$.

Evans, B. M., Hughes Jones, N. C., Mitne, M. D., and Steiner, S. (1954). Clin. Sci., 13, 305.

FALBRIARD, A., SANZ, M. C., ZENDER, R., and FraNCESCHETTI, A. (1955). Experientia (Basel), 11, 385.

HaNleY, T. (1956). Proc. roy. Soc. Med., 49, 624.

and PlatTS, M. M. (1956). J. clin. Invest., 35, 20.

Kinsey, V. E., Camacho, E., Cavanaugh, G. A., Constant, H., and McGinty, D. A. (1955). A.M.A. Arch. Ophthal., 53, 680.

KuPFer, C., LAWRENCE, C., and LinNÉR, E. (1955). Amer. J. Ophthal., 40, 673.

LANGHAM, M. E., and LEE, P. M. (1955). J. Physiol. (Lond.), 130, 27P.

MAREN, T. H. (1955). Lancet, 1, 1225. (1957). British Journal of Ophthalmology, 41, 65.

WAdsworth, B. C., YAle, E. K., and Alonso, L. G. (1954). Bull. Johns Hopk. Hosp., 95, 277.

Milne, M. D. (1956). Proc. roy. Soc. Med., 49, 624. 